\title{
The Diagnosis and Prevention of Coronavirus Disease in Dental Clinic - A Review Article
}

\author{
Bassel Tarakji ${ }^{1}$, Mohammad Zakaria Nassani ${ }^{2}$, Faisal Mehsen Alali ${ }^{1}$, Nasser Raqe Alqhtani ${ }^{1}$, Abdullah Bin Nabhan ${ }^{1}$, \\ Ali Al Rafedah ${ }^{1}$, Ali Robaian ${ }^{3}$ \\ ${ }^{1}$ Department of Oral and Maxillofacial Surgery and Diagnostic Sciences, College of Dentistry, Prince Sattam Bin Abdulaziz \\ University, Al Kharj, Saudi Arabia; ${ }^{2}$ Department of Restorative and Prosthetic Dental Sciences, College of Dentistry, Dar Al \\ Uloom University, Riyadh, Saudi Arabia; ${ }^{3}$ Department of Conservative Dental Sciences, College of Dentistry, Prince Sattam bin \\ Abdulaziz University, Alkharj, Kingdom of Saudi Arabia
}

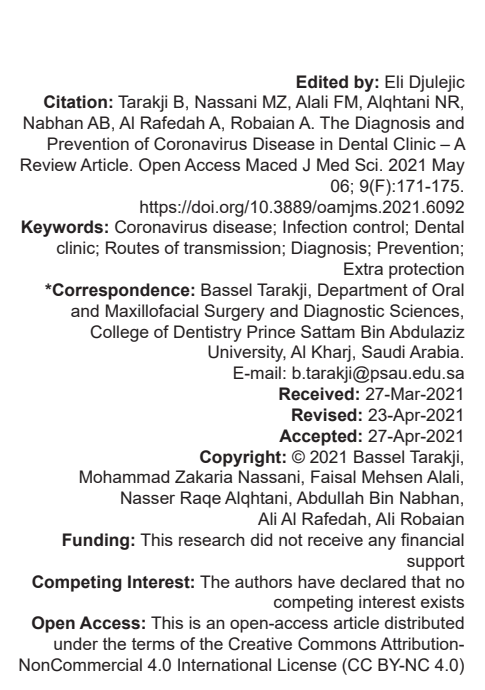

Abstract AIM: This review aims to highlight the route of transmission, clinical features, diagnosis, prevention, and protection
requirements for coronavirus disease (COVID-19) in dental clinics.

MATERIALS AND METHODS: This review is built on specific protocol, two independent reviewers, each focused on articles related to COVID-19 and infection control in dental clinics, while the third independent reviewer resolved any conflicting article of interest.

RESULTS: Respiratory droplets are the main routes of transmission of COVID-19. The main symptoms are fever, cough, and shortness of breath. Reverse transcription-polymerase chain reaction test on respiratory tract specimens is the most commonly used technique to detect COVID19. Combined nose and throat swabs and rectal swab are recommended to avoid false results. Personal protective equipment and evaluation are essential for every patient before starting any dental treatment, and following the instructions for infection control to avoid the spread of COVID19. In dental office, suspected patient with COVID-19 or presence of symptoms such as losing sense of smell and taste, in these cases dental treatment, must be postponed for 14 days. Evaluation of patient body temperature screening, and answering questions related to contact COVID19 are crucial to make the decision to start or delay dental treatment to avoid COVID-19.

CONCLUSION: Strict infection control procedures should be recommended. Patients recovered recently from COVID-19 may have treatment deferred for 28 days from onset of symptoms to avoid cross-infection. Anti-restrictive valves dental handpieces should be used to avoid cross-infection of COVID-19.

\section{Introduction}

Coronavirus disease (COVID-19) shows a fast spread of infection from one person to another [1]. The World Health Organization (WHO) has reported the outbreaks of COVID 19 in most countries in the world [2]. Most people stay at home to slow down the spread of COVID19 as much as possible. Dental practitioners are exposed to COVID-19 in their daily work. The use additional infection prevention and control practices during the COVID-19 pandemic, along with standard practices are recommended as a part of routine dental health-care delivery to all patients. These practices are intended to apply to all patients, not just those with suspected or confirmed severe acute respiratory syndrome coronavirus 2 (SARS-CoV-2) infection [2]. There is no consensus infection control protocol to protect dental practitioners, therefore, it is important to increase the level of education and knowledge of dental practitioners regarding the COVID19. Our aim in this systematic review study is to highlight the most important information related to COVID-19 available in literature relevant to the routes of transmission, clinical features, diagnosis, prevention, and extra protection procedures required within the dental clinics.

\section{Subjects and Methods}

We conducted a search of published articles from PubMed, Google Scholar databases, and in-press literature from Google search engine through snowballing. There were two independent reviewers, each focused on COVID-19, and infection control in dental clinic, and third independent reviewer resolved any conflicting article of interest. We used the keywords such as COVID-19, infection control, and dental clinics. 
Papers not written in English were excluded. Some papers were not included due to duplication. Similarly, papers that did not focus on infection control in dental clinics were excluded. Seven papers have been determined while most of the articles focused on the multiple clinical studies and reports from the WHO. We have added some papers that reported the causes of recurrent cases of COVID-19. All the most important information relevant for COVID-19 and extra protection procedures are shown in Fig. 1 and Tables 1-3.

\section{Results}

Our results are summarized in the following:

\section{The route of transmission}

COVID-19 is likely to be transmitted from contact between one human to another [3]. There is evidence that COVID-19 can be transmitted from animal to human [1], [3]. It has been reported that some dogs and cats infected with COVID-19 after contact with infected patient can also be a cause of spread of this infection [4]. Respiratory droplets are the main route to transmission of this virus [3].

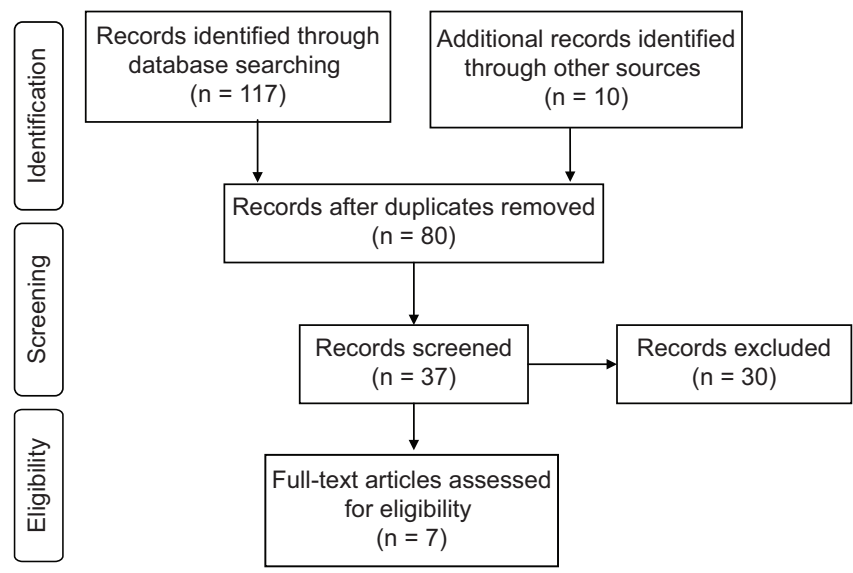

Figure 1: The used protocol for selected papers included in this study

\section{Clinical features}

Most patients with COVID-19 presented with fever, dry cough, and tiredness, while others showed fatigue, shortness of breath, headache, confusion, sore throat, and vomiting [1], [5].

Table 1: Clinical features of COVID-19 depending on Chen et al. [1], fever and cough are the most common symptoms

Fever, dry cough, shortness of breath, muscle ache, fatigue, headache, sore throat,

chest pain, diarrhea, nausea and vomiting, and loss of smell or taste may be indicator for infection with COVID-19 before manifestation of main symptoms

The prognosis of COVID-19 was poor in elderly patients and patients with pre-existing chronic diseases such as cardiovascular disease, diabetes mellitus, hypertension, and chronic pulmonary disease [6], [7]. Old age patients or those patients with medical problems needed to be referred to intensive care unit. The WHO indicated that some patient can be infected without presenting any symptoms. The incubation period for this virus ranged from 1 to 14 days [4].

\section{Diagnosis}

Depends on epidemiological details such as traveling, get-together with infected patients in the past 14 days, clinical symptoms, computed tomography image, laboratory tests, and reverse transcriptasepolymerase chain reaction tests on respiratory tract specimens to detect COVID19 in sputum, throat swabs, and secretions of the lower respiratory tract samples [8], [9].

\section{Interpretation of false results}

COVID-19 can be identified from blood and rectal swabs too other than throat swabs [10]. This study recommended taking samples from different areas of infected patients to avoid false or positive results. These false results are very critical due to the infected patients acting as a carrier and can transmit the virus to other people.

Table 2: Summary of extra protection procedures in dental clinic

\footnotetext{
1 - Wash hands before and after dental treatment for both dentist and patient

2 - Cleaning and disinfection of all the surfaces in dental clinic, patient must minimize the contact with environment surfaces such as door handle, open and close door 3 - Avoid touching eyes, nose, or mouth

4 - Use barrier protection disposal equipment

5 - Rinse mouthwash

6 - Use of anti-restrictive valves dental handpieces

7 - Avoid contact or treatment of infected patients COVID-19

8 - Avoid aerosol-generating procedures such as low-speed and high-speed handpieces 9 - Patient should not contact with all surfaces, such as door handles, by having dental staff open/close all doors
}

All the health care workers who are involved in detecting COVID-19 should pay special attention to the following points to avoid these false results such as an inappropriate collection of sputum samples, contamination of the sample, poor skills, improper laboratory equipment, not paying attention to secondary infection of patients which can induce SARS-COV-2, sampling from inappropriate site of the throat especially for throat swab sampling, missing viral load due to the early stages of the infection, bad diagnostic methods, and limited information of medical history [10], [11], [12].

Table 3: Important procedures in screening room in dental office

\footnotetext{
2 - Have you complained of signs and symptoms of COVID-19 in the past 14 days?

3 - Did you travel or contact with infected patients COVID-19 in the past 14 days

4 - Reactivation of COVID-19 can be seen in some patients after 14 days of isolation, therefore postponed of dental treatment for 28 days from onset of signs and symptoms is recommended
}

1 - Measurement of body temperature 


\section{Prevention of COVID-19}

It is recommended for infected patients with COVID-19 or close contact with infected patients to stay at home (self-isolation) for 14 days. Those patients should be observed when they complain of clinical features of COVID-19 such as fever, coughing, shortness of breath, or diarrhea [13]. Doctors have to evaluate each case individually, if the signs are mild, patients can stay isolated at home under strict observation, and for severe cases depending on the signs and symptoms, decision must be made whether to stay isolated home or to be referred to hospital for intensive care [13], [14].

\section{Reactivation of COVID-19: 14 days from the onset of symptoms may not be enough to allow dental treatment}

Dentists should be aware that the recently recovered patient from COVID-19 might still be carrying the viral load and can transmit the virus even after they have tested negative after the 14 days from the onset of symptoms and isolation [15].

\section{Loss of smell or taste}

Dentist should be aware that the loss of smell or taste functions after 14 days of quarantine and onset of the symptoms may indicate incomplete recovery that a recently recovered COVID-19 patient may still be carrying the viral load and the risk of virus transmission should not be excluded [16].

\section{Cleaning surfaces in dental clinic}

Disinfectants containing ethanol (78\%-95\%) and iodopovidone solution $(0.23 \%-7.5 \%)$ can inactivate high concentration of coronavirus within $30 \mathrm{~s}-1 \mathrm{~min}$ [17], [18], hence should be used within the dental clinics.

\section{Ventilation}

It is suggested that ventilation can reduce pathogen transmission [19]. The WHO guidelines recommended an hourly average ventilation rate of $160 \mathrm{l} / \mathrm{s} /$ patient for airborne precaution rooms [20].

\section{Extra protection procedures in dental}

\section{clinic}

All dental professionals should avoid being exposed to COVID-19 [21] by applying strict prevention procedures. The $\mathrm{WHO}$ has recommended to use face masks such as respirators N95 or FFP2 when performing aerosol-generating procedures [22]. The American Society for Testing and Materials rated medical masks to three levels of protection: Level 1 - low barrier procedures such as examination; operatory cleaning; impressions taking; laboratory trimming, finishing, and polishing; and orthodontics; Level 2 - moderate barrier procedures such as restorative/composites; endodontics; prophylaxis; sealants; scaling and root planning; and limited oral surgery; and Level 3-high barrier procedures, for instance, crown preparation; implant placement; use of ultrasonic scalers with water or medicaments; periodontal surgery; and complex oral surgery [23]. The WHO mentioned that COVID-19 might stay on surfaces from few hours to few days [4]. COVID-19 can transmit through contact with saliva and conjunctival, nasal, or oral mucosa [17].

\section{Discussion}

This study discussed the importance of infection control in the dental clinics. Although many of infection control papers related to COVID-19 have been published in literature, all of these papers comprised case reports only and no randomized control trial to show the strong evidence for the diagnosis COVID19 and clinical extra protection procedures. We think that most dental practitioner are confused regarding how to avoid cross-infection from COVID-19 in dental clinic. This pandemic has continued for more than 1 year and many dentists are still waiting to receive vaccination, hence, by following adequate precautions are the only solution. Most dental management carries the risk of exposure. Dental professionals have a risk of coming into contact with saliva, blood, oral fluid, and aerosol [24]. The dental practitioner should not treat patients infected with COVID-19. Patient in dental office showing symptoms of acute respiratory infections should be avoided. All patients in the dental clinic should first undergo screening for body temperature using a forehead thermometer to investigate any symptoms of fever, the patient must complete a questionnaire regarding COVID19. If a dentist suspects a patient with COVID-19, then the dental treatment must be delayed for 14 days. If patient does not have COVID-19, even then dental treatment can be done with extra protection procedures. Loss of taste or/and smell is an indicator for clear signs of infection with COVID-19 before the main manifestation. There is no available medication and risk of transmission of COVID-19 is still high so that emergency cases only can be treated in a dental clinics.

The infection control department of the West China Hospital of Stomatology at Sichuan University recommended hand washing before and after any dental procedure [25]. It is recommended for infected COVID-19 patients to have isolation for 28 days to ensure that there is no viral load that can transmit the infection in the dental clinic. Dentist should postpone the dental treatment up to 28 days despite the absence of signs and symptoms after 14 days for infected patients with COVID-19. 
It is recommended the use of barrier protection disposal equipment, including protective eyewear, masks such as N95 respirators, gloves, caps, face shields, and protective outwear [26], [27]. Choice of face mask should be based on nature of dental intervention taking into account that the more aerosol-/dropletgenerating procedures are required extra protection is needed [23]. Dentists may require the patient to rinse with chlorhexidine mouthwash, or mouthwash containing oxidative materials to reduce the salivary load of oral microbes and COVID-19. Furthermore, anti-retraction valves dental handpieces should be used to avoid cross-infection of COVID-19 [28], [29]. The environment of the dental clinic should be cleaned and disinfected after each patient due the long existing time of COVID-19 on surfaces.

\section{Conclusion}

General knowledge regarding the routes of transmission, diagnosis, and clinical features of COVID-19 is important for dental professionals to avoid infection with respect to COVID-19. The use of personal protective equipment, evaluation of each patient and measurement of the temperature body, and no contact with infected COVID-19 patients are major procedures to avoid COVID-19 in the dental clinic.

\section{Acknowledgments}

The author would like to thank the Deanship of Scientific Research at Prince Sattam Bin Abdulaziz University.

\section{References}

1. Chen N, Zhou M, Dong X, Qu J, Gong F, Han Y. Epidemiological and clinical characteristics of 99 cases of 2019 novel Coronavirus pneumonia in Wuhan, China: A descriptive study. Lancet. 2020;395(10223):507-13. https://doi.org/10.1016/ s0140-6736(20)30211-7

PMid:32007143

2. Coronavirus Disease (COVID-19) Situation Reports; 2020 Available from: https://www.who.int/emergencies/diseases/ novel-coronavirus-2019/situation-reports. [Last accessed on 2020 Dec 12].

3. Zhu N, Zhang D, Wang W, Li X, Yang B, Song J. A nove Coronavirus from patients with pneumonia in China, 2019. N Engl J Med. 2020;382(8):727-33.

PMid:31978945
4. Question and Answers Hub; 2020. Available from: https:// www.who.int/emergencies/diseases/novel-coronavirus-2019/ question-and-answers-hub. [Last accessed on 2020 Dec 12].

5. Guan W, Ni Z, Hu Y, Liang W, Ou C, He J. Clinical characteristics of 2019 novel Coronavirus infection in China. BioRxiv. 2020;2020:20020974.

6. Liu K, Fang YY, Deng Y, Liu W, Wang MF, Ma JP. Clinical characteristics of novel coronavirus cases in tertiary hospitals in Hubei Province. Chin Med J (Engl). 2020;133:1025-31. https:// doi.org/10.1097/cm9.0000000000000744

PMid:32044814

7. Wang D, Hu B, Hu C, Zhu F, Liu X, Zhang J. Clinical characteristics of 138 hospitalized patients with 2019 Novel Coronavirus-infected pneumonia in Wuhan, China. JAMA. 2020;323(11):1061-9. https://doi.org/10.1001/jama.2020.1585 PMid:32031570

8. Zhao W, Zhang J, Meadows ME, Liu Y, Hua T, Fu B. A systematic approach is needed to contain COVID-19 globally. Sci Bull (Beijing). 2020;65(11):876-8. https://doi.org/10.1016/j. scib.2020.03.024 PMid:32296594

9. Meng L, Hua F, Bian Z. Coronavirus disease 2019 (COVID-19): Emerging and future challenges for dental and oral medicine. J Dent Res. 2020;99(55):481-7. https://doi. org/10.1177/0022034520914246 PMid:32162995

10. Zhang W, Du RH, Li B, Zheng XS, Yang X Lou, Hu B. Molecular and serological investigation of $2019-n C o V$ infected patients: Implication of multiple shedding routes. Emerg Microbes Infect. 2020;9(1):386-9. https://doi.org/10.1080/22221751.2020.1729071 PMid:32065057

11. Sohrabi C, Alsafi Z, O'Neill N, Khan M, Kerwan A, Al-Jabir A. World Health Organization declares global emergency: A review of the 2019 novel Coronavirus (COVID-19). Int J Surg. 2020;76:71-6. https://doi.org/10.1016/j.ijsu.2020.03.036 PMid:32112977

12. Wang $Y$, Wang $Y$, Chen $Y$, Qin $Q$. Unique epidemiological and clinical features of the emerging 2019 novel Coronavirus pneumonia (COVID-19) implicate special control measures. J Med Virol. 2020;92(6):568-76. https://doi.org/10.1002/ jmv.25748

PMid:32134116

13. Yuen KS, Ye ZW, Fung SY, Chan CP, Jin DY. SARS-CoV-2 and COVID-19: The most important research questions. Cell Biosci. 2020;10:40. https://doi.org/10.1186/s13578-020-00404-4 PMid:32190290

14. Infection Prevention and Control During Health Care when Coronavirus Disease (COVID-19)" is Suspected or Confirmed; 2020. Available from: https://www.who.int/publications/i/item/ who-2019-ncov-ipc-2020.4. [Last accessed on 2020 Dec 12].

15. Tarakji B, Nassani MZ. Reactivation of COVID-19-14 days from the onset of symptoms may not be enough to allow dental treatment. Oral Dis. 2021;27 Suppl 3:789-90. https://doi. org/10.1111/odi.13487

PMid:32524708

16. Tarakji B, Alali FM, Nassani MZ. Anosmia and ageusia. Br Dent J 2020;229(3):149. https://doi.org/10.1038/s41415-020-2009-5 PMid:32811912

17. Woelfel, R, Corman V.M, Guggemos W, Seilmaier M, Zange S, Mueller MA. Clinical presentation and virological assessment of hospitalized cases of Coronavirus disease 2019 in a travelassociated transmission cluster. BioRxiv. 2020;2020:20030502. https://doi.org/10.3410/f.737508447.793572134

18. Rothe C, Schunk M, Sothmann P, Bretzel G, Froeschl G, Wallrauch C. Transmission of 2019-nCoV infection from 
an asymptomatic contact in Germany. $N$ Engl $J$ Med. 2020;382(10):970-1. https://doi.org/10.1056/nejmc2001468 PMid:32003551

19. Qian $\mathrm{H}$, Zheng $\mathrm{X}$. Ventilation control for airborne transmission of human exhaled bio-aerosols in buildings. J Thorac Dis. 2018;10 Suppl 19:S2295-304. https://doi.org/10.21037/ jtd.2018.01.24 PMid:30116608

20. Atkinson J, Chartier Y, Pessoa-Silva CL, Jensen P, Li Y, Seto H Natural Ventilation for Infection Control in Health-Care Settings. $1^{\text {st }}$ ed. Geneva: World Health Organization; 2009.

21. China to Step up Countermeasures as Wuhan Virus Outbreak Grows-can; 2020. Available from: https://www.channelnewsasia. com/news/asia/china-wuhan-pneumonia-coronavirus-outbreakchinese-new-year-12287158. [Last accessed on 2020 Dec 13].

22. Advice on the use of Masks in the Community, During Home Care and in Healthcare Settings in the Context of the Novel Coronavirus (COVID-19) Outbreak. Available from: https://www.who.int/ publications/i/item/advice-on-the-use-of-masks-in-the-communityduring-home-care-and-in-healthcare-settings-in-the-context-ofthe-novel-coronavirus-(2019-ncov)-outbreak. [Last accessed on 2020 Dec 12]. https://doi.org/10.23970/arhqepccovidmasks2

23. A Mask for All Faces: Plus, Notes about Flosser and Affordable Powered Toothbrush, Registered Dental Hygienist $(\mathrm{RDH})$ Magazine; 2020. Available from: https://www.rdhmag. com/infection-control/personal-protective-equipment/ article/16409801/a-mask-for-all-faces-plus-notes-aboutflosser-and-affordable-powered-toothbrush. [Last accessed on
2020 Dec 12].

24. Izzetti R, Nisi M, Gabriele M, Graziani F. COVID-19 transmission in dental practice: Brief review of preventive measures in Italy. J Dent Res. 2020;99(9):1030-8. https://doi. org/10.1177/0022034520920580

PMid:32302257

25. Chen J. Pathogenicity and transmissibility of 2019-nCoV-a quick overview and comparison with other emerging viruses Microbes Infect. 2020;22(2):69-71. https://doi.org/10.1016/j. micinf.2020.01.004

PMid:32032682

26. Peng $\mathrm{X}, \mathrm{Xu} \mathrm{X}$, Li Y, Cheng L, Zhou X, Ren B. Transmission routes of 2019-nCoV and controls in dental practice. Int J Oral Sci. 2020;12:9. https://doi.org/10.1038/s41368-020-0075-9

27. Ather A, Patel B, Ruparel NB, Diogenes A, Hargreaves KM Coronavirus disease 19 (COVID-19): Implications for clinical dental care. J Endod. 2020;46(5):584-95. https://doi. org/10.1016/j.joen.2020.03.008

PMid:32273156

28. Wang Y, Zhou CC, Shu R, Zou J. Oral health management of children during the epidemic period of Coronavirus disease 2019. Sichuan Da Xue Xue Bao Yi Xue Ban. 2020;51(2):151-4. PMid:32220180

29. Updated Guidance on Emergency and Urgent Care During COVID-19; 2020. Available from: https://www.rcdso.org/ en-ca/rcdso-members/dispatch-magazine/articles/5338. [Last accessed on 2020 Dec 12]. 